\title{
EL ESPAÑOL DE AMÉRICA Y COSTA RICA DESDE LA ÓPTICA DEL DR. VÍCTOR MANUEL SÁNCHEZ CORRALES
}

Alberto Barahona Novoa

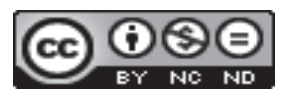

Esta obra está bajo una licencia Creative Commons Reconocimiento-No Comercial-Sin Obra Derivada 



\title{
EL ESPAÑOL DE AMÉRICA Y COSTA RICA DESDE LA ÓPTICA DEL DR. VÍCTOR MANUEL SÁNCHEZ CORRALES
}

\author{
THE SPANISH LANGUAGE IN AMERICA AND IN COSTA RICA \\ ACCORDING TO DR. VÍCTOR MANUEL SÁNCHEZ CORRALES
}

\author{
Alberto Barahona Novoa
}

\begin{abstract}
RESUMEN
Este artículo expone los fundamentos teóricos utilizados para estudiar la variedad hispánica costarricense, desde las enseñanzas del profesor Víctor Manuel Sánchez Corrales. Asimismo, se analizan varios de sus artículos sobre fonética, morfología y léxico con el fin de destacar la propuesta novedosa en los estudios dialectales de nuestro país. Por otra parte, se reseña la propuesta curricular del Dr. Sánchez Corrales para articular los estudios dialectales en el pensum de los profesionales en filología española.

Palabras clave: dialectología costarricense, lingüística hispánica, español de América, teoría dialectológica, identidad lingüística costarricense.
\end{abstract}

\begin{abstract}
This article presents the theoretical foundations used to study Costa Rican Hispanic variety, from the teachings of Professor Victor Manuel Sánchez Corrales. Also, several of his articles on phonetics, morphology and vocabulary in order to highlight the new proposal in our country dialect studies are analyzed. Moreover, the proposed curriculum Dr. Sánchez Corrales outlined to articulate dialect studies in the curriculum of the professionals in Spanish philology.

Key words: Costa Rican dialectology, Hispanic linguistics, American Spanish language, dialectological theory, linguistic identity of Costa Rica.
\end{abstract}

\section{Introducción}

Agradezco al Dr. Carlos Sánchez Avendaño, por su amable invitación para participar en este sentido homenaje en reconocimiento de la labor académica de nuestro estimado don Víctor. Vengo aquí como uno de los tantos estudiantes que conocieron los estudios dialectológicos de manos del Dr. Sánchez. Fueron muchos los años durante los cuales nuestro homenajeado

M.L. Alberto Barahona Novoa. Universidad de Costa Rica. Profesor catedrático de la Escuela de Filología, Lingüística y Literatura. Costa Rica.

Correo electrónico: jose.barahona@ucr.ac.cr

Recepción: 20- 01- 2014

Aceptación: 18- 03- 2014 
impartió la materia, al punto de que esta cátedra ha quedado asociada indudablemente a su nombre, aunque hayan sido muchos otros docentes los que la han impartido o la imparten en la actualidad. En ese dilatado período, supo inculcar el interés por esta materia y favoreció que muchos centraran sus investigaciones en este campo.

Su labor ha tenido permanencia pues esta materia se ha consolidado en nuestro pénsum. He allí uno de sus principales aciertos docentes. Su interés fue siempre institucional, pues no creó un reducto de conocimiento solo para él. Esa es la senda de los maestros: arar el terreno para que muchos sigan cultivando los arriates donde germinarán las nuevas cosechas de investigadores e investigaciones. El fin del profesor Sánchez siempre fue fortalecer la excelencia académica de esta Casa de Estudios, como imperecedera contribución a nuestro país.

$\mathrm{Su}$ calidad de maestro pervive en la conciencia de muchas generaciones. Conversando con colegas de diversas generaciones, todos coinciden en señalar a don Víctor como maestro exigente, riguroso y, a la vez, solidario; pues él tenía plena seguridad de que nos otorgaba herramientas sólidas para el conocimiento de las materias propias de nuestra disciplina. Tuve la oportunidad de iniciar mi carrera profesional al lado de filólogos y filólogas que también habían tenido al Dr. Sánchez como profesor años antes, pero en otras materias. Ellos siempre recordaban, como especial aprecio, sus clases de latín y griego, o de gramática histórica; aunque sus evaluaciones les hubieran quitado horas de sueño y tiempo de descanso los fines de semana. Esto demuestra que su norte siempre fue la formación de profesionales duchos, completos y competentes. En mi caso, a mí me tocó conocer a don Víctor como profesor de español de América y Costa Rica; y debo decirles que viví también la misma experiencia.

\section{Estudios dialectales}

Esta conciencia lúcida había sido amasada en esos años previos, por medio del estudio y la reflexión de cuáles eran las necesidades académicas que había que suplir. En consonancia con su espíritu difusor de ideas, en 1994, en la revista Káñina, publicó un breve artículo titulado "El español de América y planes de estudio en Filología española". Sus líneas son, sin duda alguna, la exposición de su ideario del papel de los estudios dialectológicos en la formación del filólogo.

Para esta corta intervención, nuevamente me voy a nutrir de sus ideas. Además, así no me arriesgo a equivocarme al presentar una visión sesgada por la admiración o - ¿por qué no?- de una mala interpretación de sus reflexiones. Sería improbable pues, con los años, estas se han convertido en guía programática para las labores de esta Unidad Académica. Sus publicaciones son parte indiscutible de su condición de mentor para todos sus estudiantes, a la que ya me referí.

La formación universitaria de calidad ha de ser intrínsecamente tanto revolucionaria y renovadora como actual para cumplir con su misión en las sociedades modernas. Pues bien, sus enseñanzas de la teoría dialectológica no han defraudado ni un ápice. Cito a don Víctor:

\footnotetext{
Al considerar el uso de la lengua española en el vasto territorio en que se habla -naciones hispanoamericanas y España, por ejemplo- o como instrumento de comunicación en el seno de distintas comunidades sociales, corroboramos la existencia de variedades lingüísticas bien definidas, copresentes en lo que entendemos por lengua española y correlacionadas con factores geográficos, la situación de uso o variables sociales. Esto ha permitido categorizar las variedades lingüísticas en tres clases de 'lenguas funcionales': diatópicas, diafásicas y diatráticas, para usar la terminología creada por Coseriu. En esta perspectiva, la lengua española es un diasistema que comprehende muchas lenguas funcionales, además de los usos oral y escrito. (Sánchez-Corrales, 1994, p. 135)
} 
Considero revolucionarias estas palabras, porque muchos de los aprendices llegamos con la intención de estudiar el ESPAÑOL, sí con mayúsculas todas sus letras, albergando la idea de la existencia de una lengua homogénea, regida por un ideal de corrección. No en vano, pretendíamos ser profesores de español. ${ }^{1}$

En esta cita, nuestro maestro menciona a Coseriu, cuyas enseñanzas dejaron de ser una mera teoría más para convertirse en una herramienta epistémica que permite un conocimiento más acabado de la relación lengua-sociedad. En las clases del Dr. Sánchez, aprendimos la doctrina del eminente rumano en diálogo con otros eminentes lingüistas como R. Hudson o bien M. Alvar. De esta manera, se articuló un sistema de voces autorizadas que describen a cabalidad el fenómeno dialectal de nuestra lengua española en América y Costa Rica. Así el objeto de estudio se convierte en realidad social, como lo señala E. Coseriu:

\footnotetext{
La lengua, por otro lado, es la condición que hace posible el hablar, es el 'producto' del hablar como tal, o el mismo 'producto' considerado sistemáticamente: es para algunos el acervo lingüístico individual y para otros el llamado acervo lingüístico social, es el sistema abstracto que gobierna el hablar, o es lo espiritual del lenguaje opuesto a lo material, lo virtual opuesto a lo concreto; es suma, o cualquier suma, de actos lingüísticos [...] (Coseriu, 1982, p. 40)
}

En esta perspectiva, el estudio de los dialectos se vuelve un desafío pues somos artífices, como miembros de una comunidad de habla, del mismo objeto de estudio. La abstracción se materializa y el estudio se enmaraña, si no se toma conciencia de la dimensión social del lenguaje.

Tomar conciencia de esta realidad multiforme, dinámica y funcional fue un reto, pues con ella se demolían años de formación primaria y secundaria; aún más de una tradición inveterada en Occidente, como también nos lo advierte el Dr. Sánchez:

\footnotetext{
La condición del idioma español, como lengua de expansión en Hispanoamérica, favoreció y privilegió una variedad como lengua por antonomasia, al considerarse, ya desde los primeros años de la Colonia, el uso lingüístico culto del español peninsular -en particular la 'lengua literaria'- toledano, primero, madrileño, después, como el modelo de corrección idiomática y de mayor prestigio social [...] (SánchezCorrales, 1994, p. 135)
}

Esta claridad meridiana de la realidad de la lengua española de América y Costa Rica, se había consolidado luego de largos años de estudio y ejercicio docente. Haciendo acopio de su formación humanística, pasa a explicarnos el origen de esta noción defendida a ultranza por los estudiosos conservadores de la lengua española, que tanto ha calado en la conciencia lingüística de los hispanoamericanos:

\footnotetext{
El anterior concepto de lengua de herencia grecolatina, mutatis mutandis, se remonta al siglo III a. C. Los sabios alejandrinos trabajaban sobre textos literarios del pasado, habiendo hecho una gran obra filológica. La admiración de las grandes obras del pasado vino en detrimento de la lengua hablada en Alejandría, al considerarla una degeneración del lenguaje. Existía la creencia de que la lengua en que habían sido escritas aquellas obras del pasado era intrínsecamente más pura, más correcta que el habla coloquial de Alejandría y de los otros centros helenísticos: así se privilegió un estilo de lengua como criterio de pureza y corrección idiomáticas, fundamentado en textos literarios. (Sánchez-Corrales, 1994, p. 136)
}

Definitivamente, las enseñanzas del Dr. Sánchez coadyuvaron a que el estudio del español de América y Costa Rica abandonara por completo esas oscuridades del pensamiento, que deslegitimaban nuestros usos lingüísticos, arrinconándolos en la etiqueta del vulgarismo, la impropiedad, el ocurrente regionalismo y el desprecio hacia nuestras identidades lingüísticas.

Para evitar seguir repitiendo este esquema de abordaje de la lengua española, las enseñanzas de don Víctor desembocaron en una entusiasta labor investigativa de esa 
lengua viva que palpita en nuestras comunidades costarricenses. Los proyectos finales de graduación, tanto de grado como posgrado, así como las investigaciones de campo se multiplicaron con el paso de los años. Se cumple así uno de los principios universitarios ineluctables: la docencia deviene en investigación. En este caso, nuestra identidad lingüística se conoce, se describe y se defiende. De esta manera, se favorece el desarrollo de la lealtad lingüística de los costarricenses por su variedad dialectal. Es como se llega aquí a otro de los fundamentos universitarios: la acción social.

Anteriormente, se afirmó que la formación universitaria ha de ser renovada para cumplir a cabalidad su misión social. Pues bien, las investigaciones de don Víctor apuntaron siempre a renovar el estado de la cuestión de lo ya conocido en los diferentes componentes de la lengua. Las asumió como una tarea didáctica, sin dejar de pensar en sus alumnos. Veamos:

No se puede concebir un profesional en filología española, en consecuencia, sin una formación rigurosa en lingüística y, en especial, en lingüística hispánica. El estudio e investigación de la lengua española, diacrónica y sincrónicamente, en sus distintos componentes -fonológico, morfológico, sintáctico, semántico y léxico- así como de las producciones textuales como prácticas comunicativas de la correspondiente sociedad, constituyen un aspecto medular en un plan de estudios de filología española. (Sánchez-Corrales, 1994, p. 135)

No haré una cita exhaustiva de sus artículos, pues ya el Dr. Antonio Leoni lo ha hecho estupendamente. Tan solo mencionaré algunos ejemplos de esta labor. En el plano de la fonología, muchos recordaremos el artículo titulado: "Escisión fonológica de /x/ en el español de Costa Rica”, publicado en la Revista de Filología y Lingüística de la Universidad de Costa Rica, en 1986. Este análisis de uno de los hechos lingüísticos característicos de nuestra variedad dialectal, no puede omitirse al estudiar este fenómeno. Gracias a esta evaluación del fenómeno de asibilación de las consonantes vibrantes, se han desarrollado nuevas investigaciones que dan cuenta de este rasgo prototípico del español intermontano central. Propone desde la lingüística estructural una escisión primaria de dichas consonantes, con lo cual nuestro dialecto ha desarrollado una verdadera innovación en el dominio hispánico:

\footnotetext{
El fonema /I/ tiene un estatus ético, similar al del fonema /y/, puesto que éste también presenta un alófono fricativo (en posición intervocálica) y otro africado (en los demás contornos de aparición). Ambos fonemas, sonoros, constituyen un subsistema palato-alveolar que, de acuerdo con la ortodoxia descriptiva, conviene interpretarlos básicamente como africados (tensos), produciéndose una variante lenis en el contorno intervocálico, cuyo resultado son las fricativas correspondientes.

Si la anterior interpretación es válida, tenemos que la escisión fonológica de /.I/, también provocó un reajuste en el subsistema de las africadas, puesto que surge una nueva red de oposiciones: en primer lugar, y si se acepta mi tesis, hay que oponer las africadas sonoras sobre la base del punto articulatorio, y éstas, por su parte, se oponen a /č/ (dorso-palatal, africada, sorda) y a / $/ \mathrm{t}^{\circ} \mathrm{I} /$ (ápico-prepalatal, africada, sorda) por la correlación de sonoridad. (Sánchez-Corrales, 1986, p. 132)
}

Se destacan en el nivel morfosintáctico: "Un problema de semántica: neutralización presente/pasado en castellano", publicado en el exterior por Studiisi cercerari lingvistice, en 1981; así como: "La ambigüedad como mecanismo del cambio lingüístico, ejemplos del español de Costa Rica”, en la Revista de Filología y Lingüística de la Universidad de Costa Rica, 1986. En la primera de ella, toma como objeto de estudio una de las formas preferidas en el español de Costa Rica para formular preguntas del tipo: ¿Qué deseaba usted? Ciertamente, su explicación se rige por los postulados de la lingüística funcional; no obstante, con este artículo se adelanta a los estudios pragmáticos de la lengua. Concluye así el Dr. Sánchez: 
En resumen, nuestra hipótesis nos ha permitido demostrar que un sistema gramatical permite la elección de las formas que, por antonomasia, son solidarias con el aspecto no terminativo, para expresar la continuidad de un proceso en el presente, neutralizándose la oposición pretérito/presente. El hecho de que en las formas conocidas como 'presentes' no se insiste sobre el aspecto no terminativo-ni tampoco sobre el terminativo- permite que cierta clase de verbos, querer, desear, necesitar, saber, por ejemplo, al entrecruzar las categorías aspecto no terminativo y tiempo presente, recurra a la estilización morfemática en referencia. (Sánchez-Corrales, 1981, p. 619)

Siempre en el plano de la morfología, sobresale el segundo artículo mencionado, a saber: "La ambigüedad como mecanismo del cambio lingüístico, ejemplos del español de Costa Rica”. En él, nuestro maestro interseca el nivel morfológico con las necesidades comunidades de los costarricenses, mediante el análisis de la enclisis de la $-n$, los (las) por lo (las) en ciertos contextos de verbo transitivo y complemento indirecto (se) con referente plural y fijación de su (suyo) con valor de usted. Para finalizar su artículo, el Dr. Sánchez explica cómo el cambio lingüístico está vehiculado por las necesidades comunicativas de los hablantes:

Las tres variaciones anteriormente analizadas nos han permitido llamar la atención sobre la vinculación
de la ambigüedad con el cambio lingüístico. Si bien es cierto que la dinámica social está estrechamente
relacionada con el cambio lingüístico, en ella no se agota la explicación de la variación lingüística
por medio de razones internas del sistema. Hay que tener presentes los factores que intervienen en la
comunicación verbal y la función lingüística respectiva, por ejemplo, el emisor, el destinatario y la
constante búsqueda de adaptar la gramática a sus necesidades comunicativas; en el caso presente, para
eliminar las vacilaciones e imprecisiones que la ambigüedad provoca. (Sánchez-Corrales, 1987, p. 166)

En el plano léxico, sin mencionar su labor como especialista y difusor de la lexicografía actual, encontramos los siguientes títulos: Concho, ¿hipocorístico, quechuismo o término peninsular? (1990), Nuevo Diccionario del Español de Costa Rica. Elementos léxicos constitutivos peninsular-europeos (1998) y Eufemismos en el español de Costa Rica (2000). En esta vertiente, conocemos al Dr. Sánchez etimólogo. Son innumerables los estudios del origen de las palabras y fraseología costarricenses. En todas sus propuestas, se manifiesta su espíritu crítico y conocedor de la estructural lexical del español. Establece las relaciones pertinentes con las lenguas amerindias que dan un cariz especial al lexicón de las variedades americanas del castellano. En su estudio sobre el vocablo concho, término que toca profundas raíces de la identidad costarricense promovida desde la doxa literaria y política, se opone a la pretendida procedencia del término latino conchula, para establecer su origen quechua. ${ }^{2}$ Se apoya en las siguientes razones: la difusión geográfica del término, condición de puente de Costa Rica, el poblamiento tardío de Costa Rica, el rasgo de contenido 'desprestigio'. Acota el profesor Sánchez-Corrales:

El hombre de ciudad, según las actitudes lingüísticas, se caracterizaría por conocer y actuar de acuerdo con los modales más refinados, por practicar las reglas de urbanidad, por hablar de acuerdo con el uso lingüístico de prestigio. El hombre de campo, por el contrario, recibiría toda la descarga negativa: no sabe hablar ni comportarse decentemente, desconoce el refinamiento de los hábitos y usos del hombre de ciudad. De ahí que concho, sobre la base del sema 'desprestigio' como continuum semántico, haya adquirido la acepción de 'grosero', 'desconocedor de las normas de urbanidad', tal como se conoce y usa hoy en día, habiendo sido desplazado por las palabras polo y, más recientemente, maicero en la acepción 'hombre sencillo del campo'. El maicero actual, a mi modo de ver, es el concho que registra Gagini 1918, mientras que el actual concho que registra Gagini 1918 no es maicero por antonomasia, sino que se aplica a toda persona cuya conducta raya en la grosería. Como derivado tenemos la palabra conchada, costarricense por excelencia, la cual significa 'grosería'. Por otra parte, polada y maicerada serán sinónimos de conchería según la acepción y uso de Aquileo Echeverría (1905). (Sánchez-Corrales, 1993, pp. 115-116) 
Siempre asociado por su preocupación por el estudio del léxico costarricense, impulsó los estudios de lexicografía en forma fundamentada y sistemática. Para ello, creó la línea de investigación denominada "Estudios de lexicografía hispano-costarricense". En este centro, se desarrollan estudios de alto nivel que se traducen en la publicación de numerosos artículos de revista y tesis. Además, se ha consolidado, con una periodicidad bianual, la celebración de los coloquios de lexicografía. Durante el año 2014, se celebrará la sétima edición. Gracias a esta profunda revisión y aplicación de los principios lexicográficos y metalexicográficos actuales, realiza un análisis exhaustivo de los principales instrumentos lexicográficos -de acuerdo con la terminología acuñada por G. Haensch-, ${ }^{3}$ que versan sobre el español costarricense. En 1988, publicó el artículo intitulado, "Lexicografía del español en Costa Rica, visión crítica", en la Revista de Filología y Lingüística de la Universidad de Costa Rica. En 2001, retoma el tema y escribe: "La lexicografía hispánica en Costa Rica: los diccionarios de lengua", en la Revista Káñina de la misma universidad.

Su obra no solo figura en los anaqueles de las bibliotecas de nuestra universidad, sino que constituyen los antecedentes de muchas de las nuevas investigaciones sobre el español costarricense. Esta es la permanencia de la obra del Dr. Sánchez Corrales en la constitución del acervo cultural lingüístico de nuestra sociedad.

En las clases de nuestro profesor emérito, las nuevas generaciones de profesionales en Filología española conocieron las nuevas tendencias de los estudios dialectológicos, colocando a la Universidad de Costa Rica en la vanguardia de la formación en este campo. Los nombres de los consagrados y los noveles estudiosos pasaron a formar parte de un repertorio conocido. Volviendo al artículo de 1994, valga citar lo siguiente:

\footnotetext{
La filología, en particular, la española, es una práctica profesional que se fundamenta en tres disciplinas básicas: la historia, la lingüística y la literatura, tal como la concibieron y ejercieron los ilustres maestros Ramón Menéndez Pidal, Amado Alonso, Ángel Rosenblat y Dámaso Alonso o, actualmente, Juan M. Lope Blanch, Rafael Lapesa, Germán de Granda, Guillermo Guitarte, entre otros. (Sánchez-Corrales, 1994, p. 135)
}

El conocimiento de estos autores no solo se logró mediante sus clases, sino también gracias a la magnífica biblioteca, que sobre el tema ha logrado conformar. Todos sus colegas, estudiantes y tesiarios han encontrado en esta nueva biblioteca alejandrina material para sus estudios. Esta colección documental es, sin duda alguna, la más completa sobre el español de América y Costa Rica con que se cuenta en el país. Por la generosidad con la que ha compartido sus queridos libros, don Víctor merece un alto reconocimiento, porque aún este esfuerzo personal nunca ha sido solo para su beneficio exclusivo sino el de toda nuestra Institución.

Por último, es imprescindible mencionar que el Dr. Sánchez es un verdadero historiógrafo de la producción de los textos sobre la variedad hispánica costarricense. Dado su cúmulo de conocimientos y experiencia, es capaz de describir y analizar los alcances de estas obras. Su análisis es un verdadero epítome útil para las futuras investigaciones. Así en 1986, presenta el artículo, cuyo nombre es "Estudios en Costa Rica sobre lengua castellana: de Gagini a Agüero", bajo el sello de la Revista de Filología y Lingüística de nuestra Casa de Estudios.

\section{Inclusión de los estudios dialectales en los programas de estudios}

En el artículo que me ha servido de hilo de Ariadna para no perder el rumbo en la extensa obra del Dr. Sánchez Corrales, nuestro homenajeado propone un perfil del profesional en Filología española. Como se afirmó anteriormente, es una visión programática 
de su ideario comprometido con nuestra querida Unidad Académica. El conocimiento del español de América y Costa Rica sustenta cada una de sus partes, a saber: funciones, tareas, conocimientos, habilidades y destrezas, así como valores y actitudes. Esta propuesta ha de ser tenida en cuenta en todo momento, a fin de aprovechar el parecer de los maestros que nos han antecedido y que nos han legado una universidad de excelencia. Transcribo a continuación los aspectos destacados en cada uno de los ítems del perfil profesional del especialista en Filología española el Dr. Sánchez Corrales (1994, p. 137):

\section{Funciones:}

a. Asesora en aspectos de la lengua en las diferentes dimensiones que se le solicitan: consultorías gramaticales, interpretación de textos, producción textual, publicidad y otras.

\section{Tareas:}

b. Promueve el uso de la lengua española en términos reflexivos y creativos.

c. Difunde el reconocimiento de la lengua como elemento básico de la identidad nacional, la comunicación, el arte y el desarrollo científico y tecnológico.

\section{Conocimientos:}

d. Domina un marco teórico que lo capacita para estudiar científicamente el lenguaje.

e. Conoce la lengua española como un diasistema dinámico, instrumento de comunicación de los hispanohablantes, con variaciones sociales, geográficas y estilísticas.

f. Conoce la lengua española en sus distintos niveles: fonética y fonología, morfosintaxis, léxico y semántica, teniendo en cuenta particularidades de variación.

g. Conoce y promueve la variante lingüística de prestigio, sus reglas de estructuración y condiciones de uso, tanto en el código oral como en el escrito.

h. Conoce los principios de evolución de la lengua española, diacronía e historia externa.

Habilidades y destrezas:

i. Es capaz de conjugar su formación humanística con los conocimientos de su disciplina para integrarlos, actualizarlos y hacerlos funcionales en su contexto histórico.

\section{Valores y actitudes:}

j. Manifiesta disposición para la investigación en su especialidad, con la conciencia de que ésta es la vía adecuada para renovar constantemente el conjunto de herramientas de que dispone en el ejercicio de la profesión, en función de las demandas que las nuevas circunstancias le imponen.

k. Conoce las implicaciones prácticas y sociales de sus conocimientos y los emplea no como fines en sí mismos, sino como medios para el mejoramiento de la condición humana.

¡Amigos, MAGISTER DIXIT! Este es un compromiso para todos aquellos que hemos decidido ejercer esta profesión.

En el apartado llamado Algunos aspectos del español de América como materia, estos nunca han de ser olvidados por quienes, en algún momento, sean profesores de esta 
materia. Ciertamente, en esa forma, nos aseguraremos de que no estamos perdiendo el norte trazado en el compromiso de formar buenos profesionales en Filología española y Enseñanza del Castellano y la Literatura.

Para finalizar, cito las conclusiones de esta publicación. No hay mejor manera de cerrar mi participación que cediendo la voz al maestro por medio de su lúcida escritura:

\begin{abstract}
Con los aspectos tratados y las reflexiones precedentes, se promueve una actitud científica ante la lengua española, sin privilegiar ninguna de sus variedades; se contribuye a una formación más rigurosa del profesional en filología española, además de despertar actitudes de lealtad y orgullo hacia las variedades lingüísticas nacionales: etnia, historia, cultura, identidad se hermanan en la lengua o la lengua en ellas. El uso lingüístico de cada nación y sus hablantes los distingue en el conjunto de pueblos centroamericanos, hispanoamericanos o peninsulares. La investigación y enseñanza de los usos lingüísticos en Hispanoamérica, con la inclusión obligatoria del español de América como asignatura en los curricula de filología española, se imponen para reafirmar la hispanoamericanidad e identidad nacional, correspondiente en el seno de los pueblos que dicen hablar español. (Sánchez-Corrales, 1994, p. 139)
\end{abstract}

\title{
4. Conclusión
}

El desafío está planteado para las próximas generaciones de profesores de lingüística hispánica en la Escuela de Filología, Lingüística y Literatura. El español de Costa Rica se ha configurado en una variedad portadora de la cosmovisión de nuestros compatriotas. Separarnos de la enseñanza de esta materia sería una especie de traición lingüística a nuestra identidad.

La lengua en sociedad y una sociedad con su propia variedad lingüística es un binomio inseparable. No es posible regresar a los cultos eurocentristas en el momento de valorar nuestros usos lingüísticos. Ciertamente, estos se nutren de la sabia de aquel dialecto nacido contra el mar cantábrico; pero, con los años, en nuestro país se ha convertido en la herramienta de comunicación propia con la que los costarricenses expresamos nuestros anhelos y realidades. En este proceso, los estudios de la envergadura del Dr. Víctor Manuel Sánchez Corrales han facilitado esa apropiación para construir nuestra identidad cultural.

\section{Notas}

1. Al respecto de la concepción polifónica del fenómeno lingüístico, R. Hudson advierte: “[...] hemos tratado un gran número de variedades lingüísticas, que incluyen 'lenguas', 'dialectos' (tanto regionales como sociales), 'registros', 'lenguas estándar', variedades diglósicas 'alta' y 'baja', 'pidgins' y 'criollos'. Hemos llegado a conclusiones esencialmente negativas acerca de las variedades. En primer lugar, hay problemas considerables de delimitación entre una variedad y otra de la misma clase (es decir, una lengua de otra, o un dialecto de otro). En segundo lugar, existen serios problemas de delimitación de un tipo de variedad de otro: lenguas de dialectos, o dialectos de registros, o 'lenguas ordinarias' de criollos, o criollos de pidgins, (Hubiéramos podido mostrar dudas semejantes en la delimitación de variedades 'estándar' y 'no-estándar'.) En tercer lugar, hemos sugerido que la única forma satisfactoria de solucionar estos problemas es evitando completamente la noción de variedad como concepto analítico o teorético, concentrándonos por el contrario en el elemento lingüístico individual. Se hace necesaria una 'descripción social' para cada elemento, precisando quién lo usa y cuándo: en algunos casos la descripción social de un elemento será única, mientras que en otros es posible que pueda generalizarse a través de un mayor o menor número de elementos. Lo más que este método se acerca al concepto de 'variedad' es en estos elementos de similar descripción social, pero sus características son más bien distintas de las de las variedades como las lenguas y los dialectos. Por otra parte, también es posible utilizar los términos como 'variedad' y 'lengua' de un modo informal, como han sido utilizados en las pocas secciones anteriores, sin ninguna intención de que se tomaran demasiado seriamente como armazones teóricos." (Hudson, 1981, p. 81) 
2. Las obras lexicográficas costarricenses han definido el término en las siguientes formas: ArturoAgüero (1996). Concho, -cha. adj. Rústico, campesino, paleto. Ú.t.c.s. Esta palabra se origina de la generalización que se le dio al hipocorístico Concho, de Concepción, como se llamó al campesino de quien procede. // 2. Grosero, palurdo, tosco, ordinario. //3. Huraño, retraído, insociable. -Carlos Gagini (2008). Concho.- Rústico, palurdo, hombre sencillo del campo. Concho es abreviatura familiar de Concepción. Nombre muy común entre nuestros sencillos labriegos. - Miguel Ángel Quesada-Pacheco (2007). Concho, -cha adj. Campesino. //2. Grosero, rudo, vil. //3. Inculto. Como se puede apreciar, todas las obras soslayan la propuesta procedencia quechua del término.

3. Afirma Haensch: "No existe, que sepamos, ni en español ni en otras lenguas indoeuropeas, ningún término genérico que abarque toda clase de diccionarios, vocabularios y glosarios. A falta de una denominación genérica comúnmente aceptada, usaremos los términos 'obras lexicográficas' e ‘instrumentos lexicográficos'.” (Haensch, Wolf, Ettinger, \& Werner, 1982, p. 103).

\section{Bibliografía}

Agüero-Chaves, A. (1996). Diccionario de Costarriqueñismos. San José: Asamblea Legislativa. Coseriu, E. (1982). Teoría del lenguaje y lingüística general. Madrid: Gredos.

Gagini, C. (2008). Diccionario de Costarriqueñismos. (4 ${ }^{\text {ta }}$ ed.). San José: Editorial Costa Rica. Haensch, G., Wolf, L., Ettinger, S. y Werner, R. (1982). La lexicografía. Madrid: Editorial Gredos.

Hudson, R.A. (1981). La Sociolingüística. Barcelona: Anagrama.

Quesada-Pacheco, M.Á. (2007). Nuevo Diccionario de Costarriqueñismos. (4 ${ }^{\text {ta }}$ ed.). Cartago: Editorial Tecnológica de Costa Rica.

Sánchez-Corrales, V.M. (1981). Un problema de semántica: neutralización presente/pasado en castellano. Studiisi Cercerari Lingvistice. 32 (6), 611-620.

Sánchez-Corrales, V.M. (1986a). Escisión fonológica de /I/ en el español de Costa Rica. Revista de Filología y Lingüística. 12 (2), 129-133.

Sánchez-Corrales, V.M. (1986b). Estudios en Costa Rica sobre lengua castellana: de Gagini a Agüero. Revista de Filología y Lingüística. 12 (1), 125-132.

Sánchez-Corrales, V.M. (1987). La ambigüedad como mecanismo del cambio lingüístico: ejemplos del español de Costa Rica. Revista de Filología y Lingüística. 13 (1), 163-166.

Sánchez-Corrales, V.M. (1988). Lexicografía del español en Costa Rica, visión crítica. Revista de Filología y Lingüística. 14 (2), 147-156.

Sánchez-Corrales, V.M. (1993). Concho, ¿hipocorístico, quechuismo o término peninsular? Káñiña. 17 (2), 113-116.

Sánchez-Corrales, V.M. (1994). El español de América y planes de estudio en Filología Española. Káñina. 18 (2), 135-140.

Sánchez-Corrales, V.M. (1998). Nuevo Diccionario del Español de Costa Rica. Elementos léxicos constitutivos peninsulares-europeos. Káñina. 23 (3), 133-141.

Sánchez-Corrales, V.M. (2000). Eufemismos en el español de Costa Rica. Káñina. 22 (3), 109-121.

Sánchez-Corrales, V.M. (2001). La lexicografía hispánica en Costa Rica: los diccionarios de lengua. Káñina. 25 (2), 11-20. 
